understand all the physiological details, we should emphasise that we are fully conversant with the clinical picture and natural history of this common disorder. The art of counselling lies in being able to judge the intelligence, education, and perception of the audience, and we frequently overestimate the patients' capacity for understanding. A recent anecdote, recorded by a respected senior paediatrician, described how he explained this syndrome carefully to a receptive and grateful parent. He later received a letter sent by her to the medical expert of a magazine (himself in another guise) in which she asked why the child's twisted and potentially obstructed gut had not been referred for operation. ${ }^{7}$ It is perhaps wise to see the patient again after the initial explanatory interview to reinforce the advice and explanation. Frequent repeat visits should, however, be discouraged. The symptom should be minimised, although not unsympathetically, but we must say that we have no curative treatment.

Nevertheless, having offered an explanation, it is not entirely logical to refuse to intervene in the hypothetical pain pathway. Unfortunately, drug treatment aimed at reducing, preventing, or abolishing colonic spasm is usually ineffective. Some patients claim beneficial results from anticholinergic preparations such as dicyclomine (Merbentyl). I do not usually initiate such treatment, but if it has been given with good effect it is justifiable to continue. A milk-free diet helps occasionally and should be tried if a temporal relationship is noted between the pain and eating or drinking dairy produce. Constipation, when present, should be treated with a stool softening agent (such as dioctyl sodium sulphosuccinate) and a gentle laxative.

The history may have uncovered stress factors in the child's background which require referral to other professionals. These include social workers, health visitors, parents' family doctor, school doctor, child psychiatrist, or psychologist. None can alter his physiological reactions, but they might be able to improve his environment.

The untreated child will not die from his complaint, but follow-up studies indicate that he is unlikely to live without it. Those children who have been given an adequate explanation and encouragement to live a full normal life have a two to one chance of eventually losing their pains, although they retain an increased susceptibility to nervous disorders in adult life. ${ }^{8}$

\section{References}

1 Kellmer Pringle, M L, Butler, N R, and Davie, R, National Child Development Study (1958 Cohort), p 184. London, Humanities Press, 1966.

2 Apley, J, and Naish, N, Archives of Disease in Childhood, 1958, 33, 165.

${ }^{3}$ McCrae, W M, in Textbook of Pediatrics, ed J Forfar and G Arneil, p 464. Edinburgh, Churchill Livingstone, 1973.

${ }^{4}$ Kopel, F B, Kim, I C, and Barbero, G J, Pediatrics, 1969, 39, 539.

${ }^{5}$ Holdstock, D J, Misiewicz, J J, and Waller, S L, Gut, 1969, 10, 19.

${ }^{6}$ Dimson, S B, Pediatrics, 1971, 47, 666.

Weller, S, World Medicine, 1975, 10, 18

${ }^{8}$ Apley, J, The Child with Abdominal Pains, 2nd edn. Oxford, Blackwell Scientific Publications, 1975.

\title{
Letter from . . . Denmark
}

\section{Paying for medicine}

\author{
FLEMMING FR $\emptyset$ LUND
}

British Medical fournal, 1976, 1, 387-388

\section{Savings on drugs}

When Danes take their doctors' prescriptions to the chemist they are used to paying for their medicines themselves-sometimes the full price but, more often, a quarter or half of it. This may seem curious to the uninitiated but there is an explanation. The traditional attitude is that to discourage overconsumption and waste people should pay at least something themselves. But, clearly, this something should not become a financial burden to the individual and should bear a reasonable relation to the condition treated.

To apportion the cost of drugs between the consumer and the "Sygesikring," which is the Danish equivalent of the British NHS, a standing committee decides which drugs deserve to be subsidised by public funds. Accordingly medicines are classified into three arbitrary groups. Group I comprises indisputably necessary drugs and group II those which are considered important but not absolutely necessary-that is, drugs whose value is less firmly established. The rest come into the third

Laerkevej 14, 4000 Roskilde, Denmark

FLEMMING FR $\varnothing$ LUND, MD, general practitioner group: how necessary these medicines are to mankind is an open question, but nobody would like to pass a verdict that they are really unnecessary.

The health service pays $75 \%$ of the cost of group I drugsantiinfective and most cardiovascular agents, to mention just a few. The cost of those in group II is shared evenly, $50 \%$ being paid by the customer and the remainder by the service. Hormone and analgesics belong to this group. The third group is not subsidised at all, and the customer must pay the full price for such things as cough linctuses, and muscle relaxants and, since 1 July 1975, antihistaminics, antacids, sedatives, and hypnotic drugs. Before this crucial date these preparations belonged to group II.

In our country as elsewhere expenditure on drugs has been rising steadily, as has concern over it. By and large, our state finances are not very healthy, and so, during 1975, our parliament felt obliged to apply the financial brakes in no uncertain manner, in every possible-and a few rather impossible-ways. A penny saved is a penny gained and thus it was officially demanded that Dkr100m (about $£ 8 \mathrm{~m}$ ) should be saved on the national drug bill. The poor drug subsidy committee had to work hard to effect this saving but eventually managed to do so with medicines which were in great demand and rather expensive too. Their therapeutic value was not rated very highly, and so subsidies were withdrawn from antihistaminics, antacids, sedatives, and hypnotic drugs. The last weeks of June saw crowds of people at doctors and chemists obtaining 
supplies of these drugs, and in particular the much-favoured benzodiazepines.

The primary aim of the cost-saving policy was not, of course, to reduce consumption of the drugs concerned, but needless to say a reduction, above all in the widespread use of psychosedatives including hypnotic drugs, would be welcomed. Whether this secondary aim is achieved remains to be seen, as official statistics are not yet available. The possibility exists, however, that prescription habits may change instead. The non-toxic benzodiazepines might be partly replaced by cheap, old-fashioned remedies such as meprobamate, and barbiturates, or even small doses of major tranquillisers. The latter are still subsidised by our health service. If the total consumption of psychoactive agents does not change (but is distributed in other drugs), it may carry undesired toxicological implications.

\section{Takeover of the benefit associations}

By April 1973 the century-old sick benefit associations were dissolved and were replaced by our present national health service, the "Sygesikring." For ages they had served the public well in close and satisfactory co-operation with doctors. Nevertheless, it was considered practicable for the state to take them over, as it already administered all other sections of health care and had done so for many years.

From 1974 negotiations took place between GPs and the health service to update the contract which had been inherited from the defunct sick benefit associations. It was assumed that only minor problems existed between the two sides, and, though negotiations went on for such a long time, no real conflict was envisaged. Even in the autumn of 1975, when difficulties arose over some aspects of the contract, the risk of a conflict was spoken of only as a bad joke.

Then, all of a sudden, in the last week of November, the GP section of the Danish Medical Association announced that it would break away from the health service on 1 December. Everybody was incredulous but no compromise was found, so since December all GPs have been practising privately with a direct financial relationship with their patients. It is indeed an odd situation to see patients paying the receptionist before leaving the surgery and, for the GP himself, it is an equally peculiar sensation personally to settle accounts with patients on home visits. To the practice staff it means a lot of extra work, book-keeping and so on, but, apart from that, life is not very different. Patients come as usual, work is done as always and they get full reimbursement at the local branch of the health service. Very little dissatisfaction is noted, though it is a nuisance for everybody. Nobody has the faintest idea when the conflicting sides will resume negotiations and perhaps we shall continue as we are for quite a while.

Some day, of course, a solution must and will be found but, deplorable though such matters are, I am not at all sure that a contractless period may not have its brighter side. Even if daily life and work goes on much as usual, the public and doctors alike now realise what was nearly forgotten-that it is in fact a great advantage for all financial aspects to be kept outside the doctor/patient relationship. And to the people in the health service, it might be beneficial for them to note that the GP service continues to function as if nothing had happened, and that a continuous contract is by no means a sine qua non.

\section{Today's Treatment}

\section{Endocrine and metabolic disease}

\section{Obesity}

\section{J F MUNRO}

British Medical fournal, 1976, 1, 388-390

\section{General considerations}

The medical management of obesity is notoriously unsatisfactory. Only a relatively small percentage of patients lose weight effectively and a large proportion of these subsequently regain weight. ${ }^{1}$ Weight loss, however, is only one aspect of managing the overweight patient, who will have sought medical advice either because of obesity or for some other reason which may or may not be a complication of obesity. The finding of a condition such as diabetes, ischaemic heart disease, or a hiatus hernia may provide a clear-cut justification for recommending weight loss. Sometimes, however, emphasis on weight loss may be unrealistic and of secondary importance when compared with other

Eastern General and Edenhall Hospitals, Edinburgh

J F MUNRO, MB, FRCP(ED), consultant physician aspects of their management, such as stopping smoking in the obese, breathless, chronic bronchitic.

Patients who seek medical advice primarily for obesity are often distressed for cultural or psychological, rather than physical, reasons. They are a self-selected group who have failed with self-imposed dietary control and often with other measures, which may have included membership of one of the various slimming clubs (these latter produce satisfactory results for many patients). ${ }^{2}$ This self-selection may possibly explain in part why results obtained in clinical practice are often disappointing. If the doctor is to help he must first try to determine the reason for the request for medical help. Patients will only reduce if they are appropriately motivated and are aware of the underlying cause of their weight gain. The direct question, "Why do you want to lose weight ?" will often provide a revealing answer. Sometimes it will show that the management should be primarily supportive as in those who have failed to appreciate that weight gain was caused by, rather than the cause of, some underlying unhappiness.

Many patients have an unrealistic concept of the expected rate of weight loss and are in danger of becoming disheartened while 